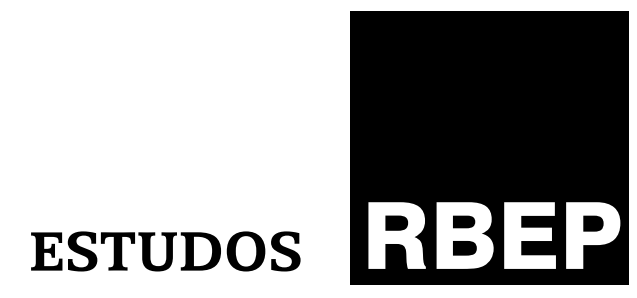

\title{
Projeto pedagógico do curso de licenciatura em Ciências da UFPR Litoral: desafios e possibilidades para uma formação emancipatória
}

Lenir Maristela Silva

Francéli Brizolla

Luiz Everson da Silva

\section{Resumo}

A crítica aos currículos fragmentados em disciplinas tem sido recorrente em inúmeras publicações nacionais. A dificuldade para a implantação de currículos não disciplinares nos cursos de ensino superior em universidades estabelecidas há décadas esbarra, principalmente, nas relações de poder dentro das universidades. O setor Litoral da Universidade Federal do Paraná (UFPR) faz parte do plano de expansão das instituições brasileiras de ensino superior e, assim, marcou seu início com o desafio de fazer diferente, ou seja, atuar com currículos não disciplinares. Nesse sentido, apresentamos detalhadamente o projeto pedagógico do curso de licenciatura em Ciências construído ao longo dos quatro anos de sua existência.

Palavras-chave: currículo; desenvolvimento regional; ensino superior 


\section{Abstract \\ Pedagogical project of the Degree in Science of the Federal University of Paraná (UFPR ) - coastal zone: challenges and opportunities for emancipatory education}

The criticism that the undergraduate curriculum is fragmented is a recurring theme on several Brazilian publications. The difficulty for the implementation of non-disciplinary curriculum in universities touches on power relations. The Federal University of Paraná (UFPR) - coastal zone is part of the expansion of Brazilian higher education institutions and has significantly affected its beginning with the challenge of not using nondisciplinary curriculum. Therefore, we present the details of the political pedagogical project of the Degree in Sciences developed over the years.

Keywords: curriculum; regional development; high education.

\section{Introdução}

A UFPR Litoral é um setor, criado em 2005, da Universidade Federal do Paraná, que no ano de 2012 completou um século de existência. O projeto político-pedagógico (PPP) desse setor teve sua gênese na plataforma para eleição da reitoria da universidade no ano de 2001, para a gestão de 20022006. A proposta foi fundada com a intencionalidade de representar mais do que a ampliação de vagas no ensino superior, fato este que por si só já seria significativo, mas instalou um projeto inovador em uma região geográfica desacreditada historicamente e com uma grande debilidade econômica (UFPR Litoral, 2008).

A implantação desse setor marca o compromisso com o litoral do Paraná - região alijada dos processos de desenvolvimento -, privilegiando a articulação entre os níveis educacionais, desde a educação básica até a pós-graduação. A instituição, localizada em Matinhos (Paraná), tem se destacado nacionalmente, desde sua inauguração, por atuar a partir de um PPP sustentado por fundamentos emancipatórios de (des)envolvimento e aprendizagem, atuando para contribuir com a construção de uma proposta curricular por meio da (re)invenção de espaços educativos, projetos, programas, dispositivos e estruturas pedagógicas que rompam com a concepção tradicional de conhecimento e a relação dissociada de homem-sociedade-natureza. Entre seus 14 cursos de ensino superior, 3 são licenciaturas.

A formação de professores no Brasil vem sofrendo alterações marcadas pela queda de qualidade e pelo distanciamento das reais necessidades do povo brasileiro, pois é própria do modelo da sociedade capitalista a produção direta e indireta de exclusão social, na qual se privilegia as ciências voltadas para a tecnologia de produção, a serviço do capital, negligenciando as demandas das ciências sociais (Cruz, 1991). 
Considerando um PPP com compromisso emancipatório, como o da UFPR Litoral, pressupõe-se que todos os cursos devam atender a expectativa de uma formação socialmente comprometida, que contribua para a superação de modelos pedagógicos curriculares disciplinares e conteudistas. Na esteira dessa problemática, apresenta-se o resultado de uma construção coletiva do projeto pedagógico do curso (PPC) de licenciatura em Ciências da UFPR Litoral. Primeiramente, é realizada uma revisão que trata de algumas problemáticas da educação básica e do ensino fragmentado das Ciências da Natureza, na busca pela justificativa de um modelo de projeto curricular não fragmentado e flexível. Na sequência, apresenta-se o PPC de licenciatura em Ciências da UFPR Litoral.

\section{A problemática da formação de professores para a educação básica e o papel da UFPR Litoral ante esses desafios}

De acordo com a pesquisa desenvolvida por Gatti e Barreto (2009), o desafio da profissionalização docente, sobretudo da educação básica, é discutido desde 1945. Nessa ocasião, a Organização das Nações Unidas para a Educação, a Ciência e a Cultura (Unesco) incorpora essa área como agenda prioritária para a garantia de uma educação de qualidade para todos, tanto no plano cognitivo quanto na dimensão humanista e ética dessa profissão.

No Brasil, vários foram os fatores que contribuíram para a complexidade da formação dos professores - culturais, políticos, econômicos, técnicos, científicos e mesmo subjetivos. De um lado, por exemplo, consideram-se a expansão da oferta da educação básica e os esforços de inclusão social, com a cobertura de estratos sociais até recentemente pouco atendidos no segmento escolar, o que provocou a demanda por um maior contingente de professores em todos os níveis da escolarização. Por outro, a modernização das sociedades e as transformações sociais adentraram os muros da escola exigindo uma formação que considere a construção de uma sociedade mais justa e democrática.

Em que pese o esforço de muitos países nos últimos decênios no sentido de organizar e estruturar carreiras do magistério com o objetivo de torná-las mais próximas do que fora estabelecido pela Recomendação OIT - Unesco em 1966, o fato é que a grande maioria dos países ainda não logrou atingir os padrões mínimos necessários para colocar a profissão docente à altura de sua responsabilidade pública para com os milhões de estudantes. O Brasil não constitui uma exceção (...) a situação atual é bastante crítica, certamente devido a omissões que se acumularam e foram progressivamente se agravando ao longo da história. As sucessivas avaliações da educação brasileira, em âmbito nacional ou internacional, indicam que o baixo rendimento escolar persiste e demonstram a magnitude e a complexidade do problema (Gatti; Barretto, 2009, p. 8).

Entre os principais desafios da formação docente, a escassez de professores para a educação básica tem sido historicamente um 
problema nacional e tem contribuído para a desqualificação da escola pública brasileira. Um levantamento do Instituto Nacional de Estudos e Pesquisas Educacionais (Inep) do ano de 2003 apontava que, para atender a demanda naquele momento, seriam necessários 235 mil professores no ensino médio e 476 mil nas turmas de $5^{\mathrm{a}}$ a $8^{\mathrm{a}}$ séries, totalizando 711 mil docentes; porém, nos anos anteriores haviam se formado apenas 457 mil nos cursos de licenciatura.

Já o atendimento à demanda de professores de áreas específicas para a segunda etapa do ensino fundamental e para o ensino médio apresenta grande repercussão nas políticas de formação docente. De acordo com o Censo da Educação Superior de 2006 (Gatti; Barretto, 2009), a oferta de cursos e as escolhas dos estudantes revertem a tradicional hierarquia que coloca no topo do currículo da escola básica o ensino de Língua Portuguesa e de Matemática, embora isso não signifique que esses componentes deixaram de ser altamente valorizados no ensino básico. Entretanto, a pesquisa realizada sugere que parcela expressiva de estudantes parece buscar os cursos de licenciatura com a perspectiva de encontrar um leque mais variado de colocações no mercado de emprego - entre outras razões, provavelmente por conta do desprestígio do magistério e de seus salários pouco atraentes. Essas hipóteses foram reforçadas em 2007 com novos dados do Censo da Educação Superior na análise do fluxo de matrículas ao longo dos últimos anos. A partir desses dados, é possível dizer que o número de estudantes formados nos cursos especificamente voltados para o magistério, como Letras, Biologia, Química, Geografia e Filosofia, diminuiu em relação a 2006.

Entre as áreas com maior escassez se encontra a de Ciências, tanto no ensino fundamental quanto no médio. Especificamente no nível fundamental, além da mencionada escassez, outro problema apontado pelo Inep é que a formação desses professores tem se dado no âmbito das Ciências Biológicas, o que acaba causando deficiências no aprendizado dos conteúdos de Física e Química. O Instituto ainda menciona que, entre as áreas de Ciências da Natureza, a única que não se encontra em situação crítica é a Biologia.

Na análise dos dados de 2007, a área de Ciências é quantitativamente mais bem representada quanto à oferta de cursos e respectivas matrículas em relação às áreas de Matemática, Química e Física. Porém, para compor o grupo dos cursos de Biologia, também foi necessário agrupar modalidades diversas tais como os denominados genericamente cursos de Ciências, Ciências Biológicas e Biologia e os cursos de formação de professores de Ciências e Biologia, sendo que predominam os destinados ao magistério $(27,6 \%)$, ainda que seja bem expressivo o percentual dos que cursam Ciências Biológicas (20,2\%).

No entanto, mesmo que no Brasil haja cursos suficientes para atender a demanda de formação de professores, isso não implica necessariamente melhoria da qualidade dessa formação, pois há outros problemas historicamente apontados na literatura. André (2002) apresenta a compilação de um vasto estudo no qual destacamos, além de outras 
dificuldades, o tratamento isolado das disciplinas específicas e pedagógicas nos cursos. Além disso, o compromisso social aparece como elemento fundamental no processo de formação do professor; no entanto, em currículos convencionais fragmentados tal componente é raro.

Segundo Ayres (2005), a tensão entre os cursos de bacharelado e os de licenciatura ainda é uma constante na maioria das universidades brasileiras, e isso deriva da justificativa da necessidade de um tempo maior para a formação do bacharel como premissa para uma graduação de qualidade. A mesma autora, ao verificar como o curso de licenciatura em Ciências Biológicas da Faculdade de Formação de Professores da Universidade do Estado do Rio de Janeiro (Uerj) vem enfrentando a tensão entre a formação para a pesquisa em Biologia e a formação para o magistério, identificou que isso lhe parece estrutural e, no seu entendimento, insolúvel, nas condições históricas atuais. Esse aspecto foi evidenciado por Menezes (apud Ayres, 2005) quando em um seminário mencionou que a universidade tem aceitado formar professores como uma espécie de tarifa que ela paga para poder "fazer ciência em paz".

Na perspectiva de superação, Carvalho (1992b) propõe a revisão das propostas curriculares dos cursos de licenciatura. O autor argumenta que isso reporta a uma abordagem dos problemas de origem social com grandes implicações pedagógicas e problemas de origem pedagógica com sérias implicações sociais. No primeiro grupo, destaca a diferença entre o contingente de alunos frequentando as universidades públicas e particulares; a desvalorização social da profissão docente; a falta de cursos noturnos nas universidades públicas; o baixo padrão educacional dos cursos de licenciatura na maioria das faculdades particulares; e a necessidade de verba para reciclar os professores dos ensinos fundamental e médio. Entre os problemas de origem pedagógica, observa que as faculdades - mesmo nas boas universidades - não estão formando bons professores para os ensinos fundamental e médio. Carvalho (1992a) defende, ainda, o papel central da prática de ensino na integração entre o conteúdo pedagógico e o conteúdo específico de formação e da práxis, da formação inicial e continuada.

Algumas alternativas apontadas nos estudos analisados por André (2002) são: a interdisciplinaridade, materializada em projetos de ação integrada; a articulação entre teoria e prática desde o início dos cursos, assumindo uma visão de unidade e totalidade do conhecimento e da convergência das ciências; a recondução do estágio supervisionado como fechamento dos cursos; e o redimensionamento das relações estabelecidas entre a universidade e a sociedade. Cruz (1991) propõe a autoconstrução dos cursos de licenciatura a partir das relações entre teoria e prática e da visão interdisciplinar, superando divisões e promovendo, por sua finalidade e princípios, um trabalho verdadeiramente coletivo entre profissionais e estudantes de várias licenciaturas.

A implantação de cursos de diferentes licenciaturas na UFPR Litoral a partir de 2008, fundamentada em um PPP comprometido com uma lógica societária de desenvolvimento regional sustentável, implica numa 
dinâmica universitária e de formação acadêmica empenhada e entrelaçada com as demandas da materialidade dos sujeitos sociais. No PPP há uma opção radical pela relação cotidiana com a escola pública como eixo fundamental - tanto na formação continuada quanto na formação de redes, ou seja, na implementação de processos de cogestão das políticas públicas.

Os princípios acima mencionados colocam a formação em permanente posição desafiadora, horizontalizada e somada com os sujeitos sociais da região, buscando conhecer-compreender-propor e agir no enfrentamento aos desafios das mazelas da questão humana nesse território, sejam sociais, culturais, ambientais ou econômicas. Nesse sentido, a construção de PPC na UFPR Litoral é pautada: (a) na ideia de um currículo flexível, sem a presença de disciplinas estanques, com arranjos que favoreçam atividades em turmas mistas entre os diversos cursos por meio das atividades de intercursos, por exemplo; (b) na valorização das interações culturais e humanísticas, materializada em espaço curricular permanente; (c) no desenvolvimento de projetos de aprendizagem, os quais possibilitam a autonomia e o protagonismo dos acadêmicos; e (d) na oferta de cursos predominantemente no período noturno.

Esse desafio de inovação pedagógica é proposto para todos os cursos e também está posto para as licenciaturas. Para fazer frente ao desinteresse dos estudantes que optam pelos cursos clássicos das áreas da Ciência (em particular Química e Física), têm sido criados os cursos de formação de professores de Ciências, numa tentativa de atrair alunos especificamente interessados no magistério, preparando-os como professores polivalentes das disciplinas da área, o que pode contribuir para suprir as lacunas provocadas pela falta de docentes habilitados, dependendo dos locais a serem atendidos. No entanto, a forte tradição da disciplinaridade que marca a identidade da docência no Brasil, segundo a qual os professores se afinam mais com as demandas provenientes da sua área específica de formação do que com as demandas gerais da escola básica, "leva não só as entidades profissionais como até as científicas a oporem resistências às soluções de caráter interdisciplinar para o currículo" (Gatti; Barretto, 2009, p. 77).

\section{A problemática do ensino das Ciências da Natureza}

O ensino-aprendizagem das Ciências da Natureza vem recebendo muita crítica no meio acadêmico devido à fragmentação curricular. O ensino de conteúdos compartimentalizados, sem contextualização e conexão com outras áreas de conhecimento, configura-se como um grande problema na formação de futuros cidadãos, conscientes de seus direitos e deveres, que possam atuar de forma crítica na sociedade. Esse tipo de currículo reduz/limita a visão de homens e mulheres, tornando-os mais fáceis de serem dominados pela elite hegemônica (Silva, 2009).

Poucas vezes nas escolas se discute a contextualização dos saberes científicos a fim de compreender como e por que tal conhecimento surgiu 
numa determinada época e local. Para o entendimento do processo de produção do conhecimento científico na sociedade contemporânea, é necessário considerar a dimensão política dele. O fenômeno vida, por exemplo, é trabalhado no ensino de Ciências e no de Biologia dentro de uma perspectiva que desconsidera os aspectos políticos e sociais. Discute-se a vida como se ela fosse determinada apenas pelos fatores internos ao organismo, deixando de lado os fatores externos que interagem e a modificam (Cunha, 1988).

Os programas de Física, por sua vez, são pautados em conteúdos tratados numa rígida sucessão linear e desarticulados, tendo como objetivo principal a precisão do cálculo e a crença na repetição como meio eficaz de construção do conhecimento, não oferecendo espaço para criação e recriação (Silva, 2009). Nos Parâmetros Curriculares Nacionais (Brasil. MEC, 1999), é mencionado que o ensino de Física é, frequentemente, realizado mediante a apresentação de conceitos, leis e fórmulas, de forma desarticulada, distanciados do mundo vivido pelos alunos e professores e não só, mas também por isso, vazios de significados. Privilegia a teoria e a abstração desde o primeiro momento em detrimento de um desenvolvimento gradual da abstração que, pelo menos, tenha como ponto de partida os exemplos concretos. Há uma ênfase na utilização de fórmulas, em situações artificiais, desvinculando a linguagem matemática que elas representam de seu significado físico efetivo.

O ensino de Química não é diferente do de Física, pois o currículo é conteudista, o conhecimento é essencialmente acadêmico e a metodologia enfatiza a memorização de fórmulas, classificação, regras, cálculos repetitivos que parecem só ter utilidade para o vestibular. Como muito bem observa Schnetzler e Aragão (1995), o ensino de Química continua sendo quase que exclusivamente para a retenção de enormes quantidades de informações passivas, com o propósito de que essas sejam memorizadas e devolvidas nos mesmos termos em que foram apresentadas na hora dos exames, por meio de provas, testes, exercícios mecânicos repetitivos.

É fácil perceber que, para muitos alunos, aprender Química tornou-se uma verdadeira angústia, pois não compreendem a finalidade prática da maioria dos conteúdos. Conforme Justi e Ruas (1997), os alunos não entendem a Química como um todo, mas como pedaços isolados de conhecimentos utilizáveis em situações específicas e, assim, apenas reproduzem fragmentos de conhecimento. É lamentável que o ensino de Química leve os alunos a memorizar conteúdos que não conseguem entender, enquanto poderiam estar relacionados com fatos concretos do dia a dia, promovendo aprendizagens que seriam úteis na vida diária. Segundo Demo (1997), o que se aprende na escola deve aparecer na vida.

Tal qual a Física e a Química, a Biologia normalmente é ensinada em nossas escolas de forma fragmentada, com conotação memorística e destituída de abordagem histórica (Selles; Ferreira, 2005, Pedrancini et al., 2007, Goldbach; El-Hani, 2008). A Biologia divide-se em diferentes áreas e, inclusive, entre elas não há conexão. Esse modo de ensinar Biologia desconectado das outras ciências e dela mesma faz com que o estudante 
não consiga representar os fenômenos naturais de forma integrada, por exemplo, quando se estuda a estrutura molecular do DNA, a impressão que se tem é a de que os alunos o entendem como um conjunto de letras (A-T, $\mathrm{C}-\mathrm{G}$ ). Esse ponto de vista é sustentado por algumas pesquisas em ensino de Biologia que indicam uma confusão entre conceitos de célula, molécula, átomo e tecido por alunos da educação básica (Caballer; Gimenez, 1992, Pedrancini et al., 2007).

Todas essas questões justificam a necessidade do desenvolvimento de propostas para formação de professores de Ciências da Natureza para a educação básica que busquem a interdisciplinaridade e a contextualização em suas práticas, para a construção de conhecimentos significativos (Andreatta; Meglhioratti, 2010). De maneira geral, é necessário que o ensino das Ciências eduque os seres humanos numa fraternidade que se estenda a todos os demais, independentemente de preconceitos que se constituem como tal, a partir da diversidade cultural e econômica. Cultura e conhecimento científico geram poder, e está nas mãos dos educadores a possibilidade de construir uma sociedade-mundo. A consciência não é inata, pode ser construída a partir do conhecimento científico e suas relações com o social. Pode produzir cidadãos protagonistas que, com a posse do conhecimento científico e de sua utilidade, sejam capazes de escolher e assumir, além de uma futura profissão, seu papel social. Negar esse conhecimento aos menos favorecidos, com a alegação de que eles não se interessam por ele, é condená-los a permanecer na situação em que se encontram, é negar-lhes o acesso ao poder. É nesse ponto que os professores das Ciências da Natureza têm grande responsabilidade; quando os educadores refletirem sobre esse potencial do ensino para além dos conteúdos tradicionais, estarão contribuindo com a formação de indivíduos com identidades próprias e capazes de conviver num mundo repleto de diversidade. Quando se deixa de lado o caráter imediatista do conhecimento pelo conhecimento ou para a prova, pode ser visto como resultado uma nova geração de aprendizes, que, sem a pretensão de que mudem o mundo, sejam capazes de mudar suas próprias vidas (Zuliani, 2007).

\section{Uma proposta de inovação curricular e superação de desafios: o curso de licenciatura em Ciências da UFPR Litoral}

O referido curso é ofertado desde 2008, como modalidade presencial, com regime de matrícula anual, com duração mínima de quatro anos, no período noturno e com carga horária total de 3.360h. A construção do projeto pedagógico desse curso foi iniciada em 2008, sendo orientada pelo PPP institucional da UFPR Litoral e com a participação dos discentes e docentes do curso. O estudante egresso, após cumprir todo o curso com conceito e frequência suficientes, alcançando assim todos os objetivos, receberá o diploma de licenciado em Ciências.

A proposta educacional do curso se efetiva por meio de três eixos pedagógicos: Fundamentos Teórico-Práticos (FTP), Projetos de 
Aprendizagem (PA) e Interações Culturais e Humanísticas (ICH). Em todas as fases do curso, o estudante tem contato direto com a realidade da educação pública local. Além disso, é colocado em situações que propiciam a construção do conhecimento integrado da área das Ciências Naturais (Física, Química e Biologia) com a área dos fundamentos da educação pública e suas implicações culturais, humanas e éticas. A partir dessa experiência, o aluno propõe e executa ações integradas no ensino de Ciências, transformando-se em agente emancipado e com possibilidades de contribuir com a melhoria da realidade local.

O profissional licenciado em Ciências estará capacitado, principalmente, para atuar como professor na educação básica em escolas públicas e privadas, trabalhando de forma interdisciplinar, estimulando o raciocínio crítico e a criatividade dos estudantes no que se refere às questões fundamentais das Ciências Naturais e da Educação. Esse profissional contribui com a construção do conhecimento dos estudantes com ênfase na realidade local, levando em consideração a diversidade e a pluralidade. Depois de formado, o egresso atua como professor da educação básica e tem competência para planejar e executar projetos científicos e educacionais em instituições públicas, privadas e de terceiro setor.

O curso objetiva:

- oportunizar aos estudantes a compreensão do papel social e político da escola e da profissão professor e o conhecimento dos processos de investigação, que possibilitem a constante reflexão-ação como elemento de aperfeiçoamento profissional;

- favorecer a compreensão da profissão professor na perspectiva prevista na legislação, para uma atuação multidisciplinar e em campos específicos do conhecimento, tendo a realidade local como ponto de partida e retorno da problematização e intervenção;

- desenvolver o processo educativo na sua totalidade, baseado na ação investigativa, no diálogo com o conhecimento sistematizado e na intervenção social, constituindo a práxis formativa;

- oferecer programas de formação para os professores da rede pública, de ensinos fundamental e médio, orientados para o desenvolvimento educacional, sociocultural e econômico da região geoeconômica;

- possibilitar aos estudantes a instrumentalização com suporte científico na perspectiva de uma formação emancipatória, que lhes possibilite a construção de conhecimentos para o autogerenciamento de suas atividades, gestão de pessoas, eticidade nas relações sociais, capacidade empreendedora e interventiva de sua realidade social;

- construir e difundir conhecimentos nas áreas das Ciências da Natureza e da formação de professores, entendendo-os em uma lógica dialética do global com o local, a partir de suas realidades 
concretas, possibilitando que os conhecimentos locais tencionem os globais e estimulem a criação e o fortalecimento da cultura local, em um contexto de relações democráticas e éticas na perspectiva de participação dos diversos segmentos da sociedade;

- oportunizar avaliações cujas finalidades sejam a orientação do trabalho dos formadores, a autonomia dos futuros professores em relação ao seu processo de aprendizagem e a qualificação dos profissionais com condições de iniciar a carreira;

- difundir o comprometimento com os valores inspiradores da sociedade democrática.

O curso utiliza como metodologia de ensino a aprendizagem por projetos orientada pela lógica do PPP da UFPR Litoral que busca superar os pressupostos da modernidade e se lançar na construção de um projeto inovador e emancipatório. Para tal, toma como princípio a reflexão acerca da realidade concreta do lugar, como fonte primeira, para, em diálogo com o conhecimento sistematizado, tecer a organização curricular e o desenvolvimento de projetos que devem partir dos alunos e envolver os professores e a comunidade (UFPR Litoral, 2008).

Diferentemente do entendimento de conhecimento que preponderou na modernidade, esse projeto se estrutura pedagogicamente concebendo o conhecimento como uma totalidade articulada, decorrente da reflexão e do posicionamento a respeito da sociedade e sua realidade concreta envolvendo a educação e o homem. Obedecendo a esse princípio, o PPP articula seu currículo em três grandes fases: 1) conhecer e compreender; 2) compreender e propor; e 3) propor e agir. Tal metodologia visa à modificação do espaço acadêmico tradicional, transformando-o num ambiente interativo, aberto às suas múltiplas dimensões e realidades. $\mathrm{O}$ trabalho por projetos traz uma nova perspectiva para compreensão do processo de ensino-aprendizagem. Adquirir conhecimentos deixa de ser simplesmente um ato de memorização, e ensinar deixa de ser a mera transmissão de conhecimentos prontos. Nesse posicionamento, todo conhecimento é construído em estreita relação com o contexto em que é utilizado, sendo, portanto, impossível de separar os aspectos cognitivos, emocionais e sociais desse processo.

A partir dessa metodologia, aposta-se que o aluno aprenda no processo de produzir, de levantar dúvidas, de pesquisar e de criar relações, que incentivem novas buscas, descobertas, compreensões e reconstruções de conhecimento. Já para o professor, a meta é ultrapassar a simples postura de repassar conhecimentos para ser um mediador na (re)construção do saber, contribuindo para que o aluno possa encontrar sentido naquilo que está aprendendo. O papel do docente nesse caso é o de mediador-problematizador, já que na metodologia por projetos a pesquisa é o princípio educativo. Os momentos coletivos com os estudantes não podem prescindir do diálogo. O aluno tem uma caminhada, 
um universo cognitivo e afetivo, tem sua cultura, história e contexto de vida e, portanto, um processo particular de aprendizagem. O professor precisa ter clareza de sua intencionalidade pedagógica e saber intervir no processo de aprendizagem do aluno para garantir que os conceitos sejam compreendidos e sistematizados por ele.

A metodologia por projetos exige articulações interdisciplinares que implicam aprendizagens que extrapolam o tempo e o espaço físico da sala de aula e da escola e deve promover a interação das diversas áreas do conhecimento.

Embora seja pedagogicamente inadequado estabelecer etapas de uma metodologia de ensino por projetos devido a sua característica de processo em constante movimento, no curso de Ciências cada turma desenvolve uma caminhada própria. Abaixo, descrevem-se os princípios metodológicos desse processo:

- cada série tem um professor responsável pelo acompanhamento de todas as atividades dos estudantes, pelo menos, ao longo de 1 ano. Dessa forma, esse docente participa de todas as atividades da turma, realizando registros, reelaborando o planejamento, informando os outros professores e a câmara do curso sobre o andamento da turma. Além disso, outros docentes, de acordo com o projeto de estudo que estiver sendo desenvolvido, também participam da mediação;

- na primeira série, os estudantes são estimulados a dialogar a partir de diversas atividades propostas (discussão de vídeos, textos, palestras, saídas a campo, etc.), conforme o objetivo da série. Ao final do primeiro semestre, os alunos já tiveram a oportunidade de obter uma boa compreensão do PPP do setor, do PPC do curso, da metodologia de ensino por projetos, dos principais fundamentos das Ciências e da Educação. Com base no reconhecimento regional, eles podem estabelecer o projeto de estudo da turma com a mediação do professor responsável, levando sempre em consideração o objetivo e as temáticas da série;

- a primeira série é um momento sempre tensionado pelas expectativas dos estudantes quanto ao PPC do curso, já que a maioria está habituada a uma metodologia em que, de modo geral, não os coloca como sujeitos do processo de ensino-aprendizagem. A tensão está justamente no desconforto que causa a saída de um processo passivo, em que os estudantes recebem sínteses de conhecimentos reproduzidos, para um processo ativo, em que aumenta exponencialmente a necessidade de participação;

- como premissa básica, o projeto da turma sempre deve partir da história de vida dos estudantes e da problematização da realidade local, preferencialmente, utilizando-se das diferentes áreas do conhecimento das Ciências da Natureza e da Educação, com 
potencial possibilidade de construção de novos saberes. O projeto não é uma atividade proposta pelo professor com tema dirigido resultando numa mera apresentação de trabalho, mas algo construído coletivamente pela turma, mediado pelos docentes;

- a partir do projeto de estudo, o coletivo realiza um planejamento das atividades que poderão ser desenvolvidas para atingir os objetivos. Para exemplificar, um projeto de estudo que tenha como temática as "metodologias de ensino de Ciências utilizadas nas escolas locais" implicará o coletivo na busca de bibliografias essenciais a serem estudadas, de locais e pesquisas a serem investigados, de professores que serão convidados para as atividades de fundamentação teórico-práticas;

- no que diz respeito ao registro, ao se aproximar do final do semestre, volta-se aos objetivos e ao cronograma a fim de rever/ readequar o planejamento. Além disso, tudo o que acontece é registrado em portfólios produzidos individualmente pelos estudantes. Os materiais coletivos e individuais e o desenvolvimento do projeto são avaliados coletivamente, e delineia-se uma perspectiva de projeto para o semestre seguinte, no qual, retoma-se, problematiza-se, remete-se ao PPC para garantir o atendimento às temáticas e aos objetivos e, assim, segue-se com um novo projeto ou até a continuidade do anterior, se for o caso;

- em termos de avaliação processual, por fim, esta é realizada semestralmente para os estudantes do curso e segue os princípios do Sistema de Avaliação do Setor Litoral da UFPR, o qual se centra em processos com múltiplos objetivos, por meio de indicadores progressivos.

Em suma, acredita-se que a formação dos alunos não pode ser pensada apenas como uma atividade intelectual. É um processo complexo, no qual conhecer e intervir no real são elementos de aprendizagem intimamente relacionados. Ao participar de um projeto, o aluno está envolvido em uma experiência educativa em que o processo de construção de conhecimento está integrado às práticas vividas. Esse aluno deixa de ser, dessa forma, apenas um aprendiz do conteúdo de uma área qualquer. Ao desenvolver uma atividade complexa, ele está, ao mesmo tempo, apropriando-se de um determinado objeto de conhecimento cultural e formando-se como sujeito cultural. Isso significa que fica impossível homogeneizar os alunos, desconsiderando seus modos de viver, suas experiências prévias, sua história de vida, desvinculando-os do contexto sócio-histórico que os formou. Evidentemente, uma metodologia tão complexa exige um acompanhamento constante, por isso, ocorrem reuniões pedagógicas semanais para que estudantes e professores relatem o andamento dos projetos das turmas, o que muitas vezes pode resultar em reavaliações pela turma e pelo professor responsável. 
Atualmente, a educação superior conta com uma normatização de diretrizes curriculares para a graduação que visa nortear as instituições nas elaborações curriculares dos cursos e que permite ultrapassar o modelo de currículos mínimos, ou seja, aquele conjunto fixo de disciplinas e carga-horária, de caráter obrigatório. A partir dessa diretriz, considerada uma abertura legal, há a possibilidade da construção de currículos considerando novos paradigmas de conhecimento. Assim, o curso de Ciências adotou o Mapa Conceitual (Figura 1) para expressar a noção de formação didático-pedagógica defendida, caracterizando também a compreensão da ciência como construção humana, historicamente situada, inter-relacionada, organizada e reorganizada por e entre sujeitos. Portanto, o Mapa Conceitual substitui a "grade curricular" calcada em uma visão de ciência fragmentada; no projeto pedagógico em tela, a referência é uma concepção de currículo como um conjunto articulado de conhecimentos e saberes historicamente construídos e em construção que fazem parte do processo de formação pessoal e profissional como um todo. Dessa maneira, os eixos temáticos desenvolvidos ao longo do curso possibilitam uma sólida formação profissional-pessoal, capaz de fazer diferença na construção de uma sociedade mais democrática e socialmente mais equânime.

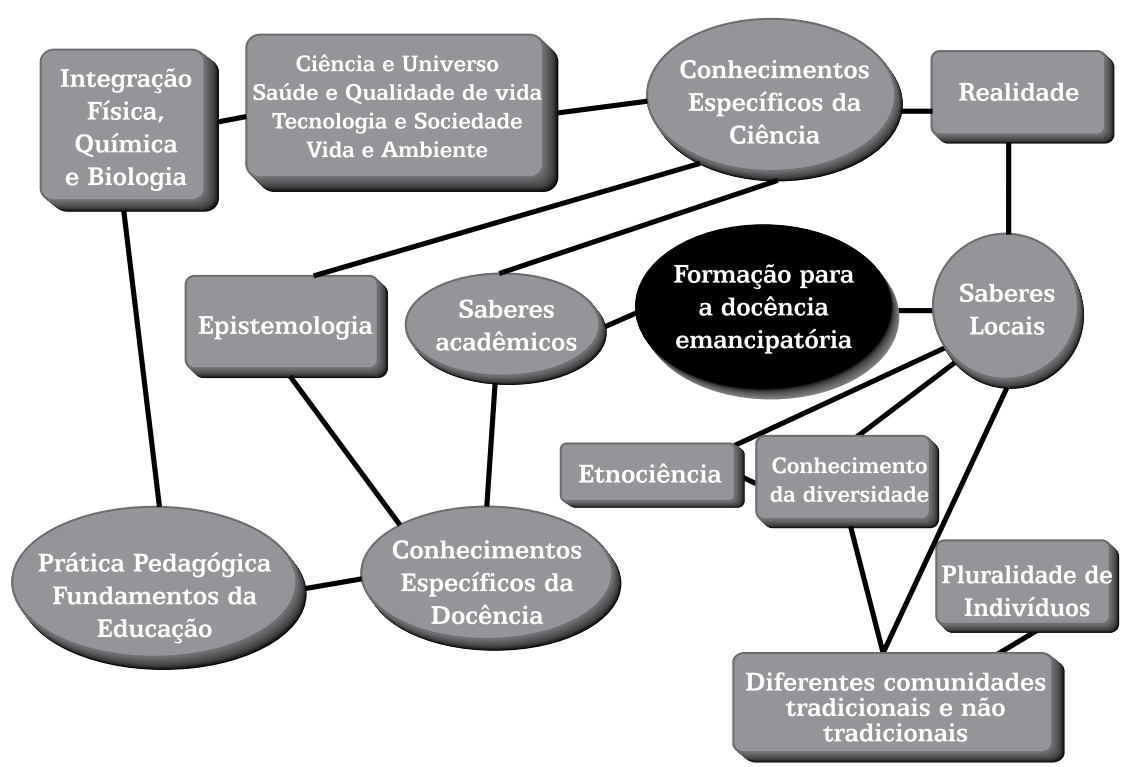

\section{Figura 1 - Mapa Conceitual do Curso de Licenciatura em Ciências da UFPR} Litoral - 2012

O desenho curricular fundamentado na educação por projetos permite que o estudante construa o saber, integrando diversas áreas do conhecimento; por isso, essa metodologia implica a construção de um currículo flexível, caracterizado da seguinte maneira no curso de licenciatura em Ciências: 
- para além dos Fundamentos Teórico-Práticos (FTP) específicos, o estudante organiza o seu cotidiano nos demais espaços semanais: as Interações Culturais e Humanísticas (ICH) e o Projeto de Aprendizagem (PA). O aluno é incentivado a perceber criticamente a realidade, compreender os diversos aspectos que a estruturam e estabelecer ações consoantes com as situações da realidade local;

- trabalho teórico com temáticas amplas pertinentes à formação de professor de Ciências, já que o trabalho por projetos rompe com o paradigma da disciplinaridade e opta, portanto, por lidar com espaços de formação que têm como principal articulador os projetos de aprendizagens, originados na realidade concreta do meio em que estão inseridos. Esses projetos possibilitam o diálogo com os fundamentos teórico-práticos, que empiricamente já os constituem e se expandem ao abarcar as interações culturais e humanísticas no espaço de troca com a comunidade externa e com outros cursos. Portanto, o currículo contempla em seus espaços a educação como totalidade, objetivando superar a proposta fragmentária da pesquisa, do ensino e da extensão;

- os FTP não possuem uma sequência linear ou pré-definida, ou seja, não há pré-requisitos no currículo. A cada semestre letivo, a turma pode fazer uma opção por uma temática prevista no currículo baseada no momento histórico-social da realidade e nas características da turma. No entanto, findados os quatro anos de curso, todas as temáticas e os objetivos do currículo deverão ter sido atendidos;

- o papel dos conteúdos e tempos está intrinsecamente conectado com a participação dos indivíduos como sujeitos de processos culturais, econômicos e acadêmicos da sociedade e das instituições de educação.

Considerando a categoria da totalidade inerente ao PPP do setor Litoral da UFPR, como já observado no Mapa Conceitual (Figura 1), a Formação para a Docência é o eixo central do curso e, portanto, esse currículo pretende evitar a dicotomia entre conhecimentos pedagógicos e conhecimentos específicos e considerar a cultura escolar ${ }^{1}$ como um dos elementos centrais da prática pedagógica em Ciências. Desse

${ }^{1}$ Cultura escolar é aquela que conforma a escola de uma maneira muito particular, com uma prática social histórica própria e única. Os principais elementos que desenhariam essa cultura seriam os atores (famílias, professores, gestores e alunos), os discursos e as linguagens (modos de conversação e comunicação), as instituições (organização escolar e o sistema educativo) e as práticas (pautas de comportamento que chegam a se consolidar durante um tempo) (Silva, 2006). modo, os conhecimentos pedagógicos são transversais ao curso devendo, obrigatoriamente, dialogar com os conhecimentos específicos integralmente.

O fluxograma do curso de licenciatura em Ciências (Figura 2) expõe de modo sintético a composição do curso. Evidentemente, neste artigo não se pretende apresentar detalhamento de ementas e bibliografias, já que o fundamental é a questão metodológica e a concepção curricular. O PPC atende as diretrizes curriculares nacionais para a formação de professores da educação básica, em nível superior, curso de licenciatura, graduação plena e todas as demais normas obrigatórias do Ministério da Educação. 


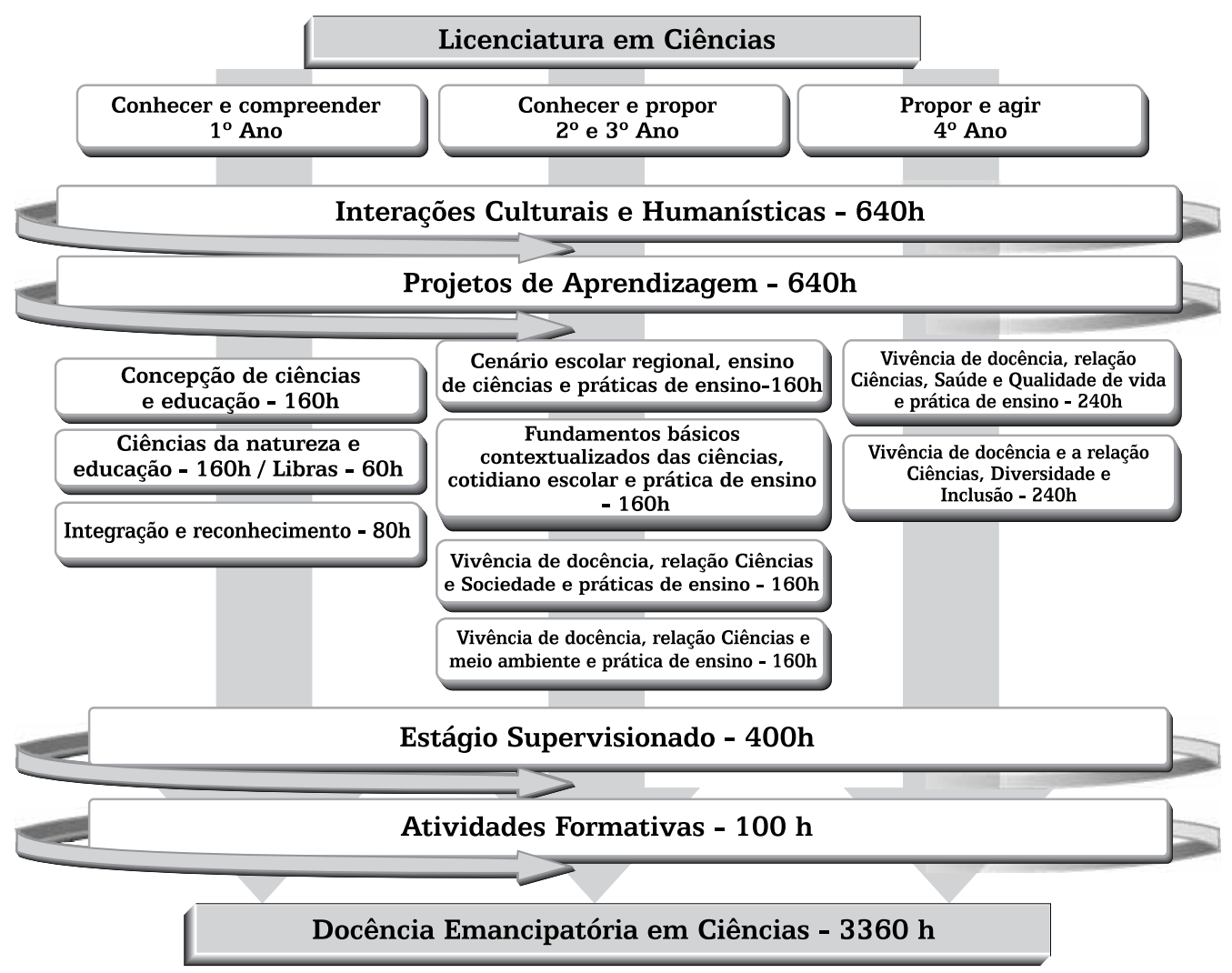

Figura 2 - Fluxograma da Organização Curricular do Curso de Licenciatura em Ciências da UFPR Litoral - 2012

\section{Reflexão final}

A construção de um currículo para o curso de licenciatura em Ciências da UFPR Litoral foi um esforço educacional coletivo, em constante movimento dialético de construção-reconstrução, idealizado para atender aos princípios político-pedagógicos do setor dessa instituição de ensino superior que já marca um século. Além disso, é reflexo de um amadurecimento profissional a respeito do ato educacional como um todo e das implicações dos currículos que formam os docentes da escola básica a partir da interação desse projeto de ensino superior com a comunidade em que está inserido.

Mediante os desafios da educação básica e da formação docente, expostos, aceitou-se o desafio de construir um PPC que avança em, pelo menos, duas questões historicamente problemáticas e deficitárias na formação na área das ciências: o foco na formação de professores e a opção por uma abordagem problematizadora e humanizada sobre o papel social da Ciência. Conforme as diretrizes para o Enade 2008, adota-se como referência um perfil profissional "(...) com consciência da importância da difusão científica, do seu papel como educador, de manter uma formação continuada, e de ser agente transformador da realidade, compreendendo 
a ciência como uma atividade social com potencialidades e limitações" (Gatti; Barretto, 2009, p. 150-151).

Assim, convergindo com a atual política nacional para a formação de profissionais do magistério da educação básica (Decreto nº. 6.755/2009), o PPC de licenciatura em Ciências da UFPR Litoral inova em sua estrutura acadêmica e curricular e nos percursos formativos desenhados, no sentido da superação de problemas de fundo da educação nacional que também são regionalizados no Litoral do Paraná, rompendo com estruturas tradicionais para uma efetiva transformação nas ações formativas.

O desafio que se coloca para cada um dos egressos desse curso, portanto, é contribuir com a (re)construção da cultura escolar na medida em que, ao tomarem para si uma visão de mundo emancipatória, possam ser sujeitos na mediação da transformação da prática social numa perspectiva de inclusão, equidade e justiça social, ou seja, de firmar seu compromisso profissional com a sociedade (Freire, 1979).

\section{Referências bibliográficas}

ANDRÉ, Marli Eliza D. A. (Org.). Formação de professores no Brasil (1990-1998). Brasília: MEC/Inep/Comped, 2002.

ANDREATTA, S. A.; MEGLHIORATTI, F. A. Integração conceitual do conhecimento biológico por meio da Teoria Sintética da Evolução: possibilidades e desafios no ensino de Biologia. 2009. (Programa de Desenvolvimento Educacional). Disponível em: < http://www.nre.seed. pr.gov.br/uniaodavitoria/arquivos/File/Equipe/Disciplinas/Biologia/ oficina/SAIONARAIntegracaoconceitual.pdf> . Acesso em: 10 out. 2010.

AYRES, A. C. M. As tensões entre a licenciatura e o bacharelado: a formação dos professores de Biologia como território contestado. In: MARADINO, M. et al. (Org.). Ensino de Biologia: conhecimentos e valores em disputa. Niterói: Eduff, 2005. p. 182-197.

BRASIL. Ministério da Educação e Cultura (MEC). Parâmetros curriculares nacionais. Brasília, 1999.

CABALLER, M.; GIMÉNEZ, I. Las ideas de los alumnos y alumnas acerca de la estructura celular de los seres vivos. Enseñanza de las Ciencias, Barcelona, v. 10, n. 2, p. 170-180, 1992.

CARVAlHO, Anna Maria Pessoa de. Memórias da prática de ensino. Revista da Faculdade de Educação, São Paulo, v. 18, n. 2, p. 247-252, jan./dez. 1992a. 
CARVALHO, Anna Maria Pessoa de. Reformas nas licenciaturas: a necessidade de uma mudança de paradigmas mais do que de uma mudança curricular. Em Aberto, Brasília, v. 12, n. 54, p. 51-64, abr./ jun. 1992b.

CRUZ, Léa da. Visões e versões: a formação de professores. Tecnologia Educacional, Rio de Janeiro, v. 20, n. 101, p. 64-69, jul./ago. 1991.

CUNHA, Reinaldo Montalvão de M. Ensino de biologia no $2^{\circ}$ grau: da competência "satisfatória" a nova competência. Educação \& Sociedade, n. 30, p. 134-153, ago. 1988.

DEMO, Pedro. Educar pela pesquisa. 3. ed. Campinas, SP: Autores Associados, 1997.

FREIRE, Paulo. Educação e mudança. 12. ed. Paz e Terra: Rio de Janeiro, 1979.

GATTI, Bernardete A. (Coord.); BARRETTO, Elba Siqueira de Sá. Professores do Brasil: impasses e desafios. Brasília: Unesco, 2009.

GOLDBACH, Tânia; EL-HANI, Charbel Niño. Entre receitas, programas e códigos: metáforas e idéias sobre genes na divulgação científica e no contexto escolar. Alexandria, Revista de Educação em Ciência e Tecnologia, Florianópolis, v.1, n.1, p. 153-189, mar. 2008.

JUSTI, Rosária da Silva; RUAS, Rejane Mitraud. Aprendizagem de Química reprodução de pedaços isolados de conhecimento? Revista Química Nova na Escola, pesquisa n. 5, p. 24-27, maio 1997.

PEDRANCINI, Vanessa D. et al. Ensino e aprendizagem de Biologia no ensino médio e a apropriação do saber científico e biotecnológico. Revista Electrónica de Enseñanza de las Ciências, v. 6, n. 2, p. 299-309, 2007.

SANTOS, Hélio et al. O preconceito contra minorias de ser enfrentado com políticas compensatórias (ações afirmativas)? Folha de S. Paulo, São Paulo, Opinião, p. 3, 6 jul. 1966.

SCHNETZLER, Roseli Pacheco; ARAGÃO, Rosália Maria Ribeiro. Importância. Sentido e Contribuições de Pesquisa para o Ensino de Química. Revista Química Nova na Escola, pesquisa n. 1, p. 27-31, maio 1995.

SELLES, Sandra Escovedo; FERREIRA, Márcia Serra. Disciplina escolar Biologia: entre a retórica unificadora e as questões sociais. In: MARANDINO, Martha; FERREIRA, Márcia Serra; AMORIM, Antônio 
Carlos (Org.). Ensino de Biologia: conhecimentos e valores em disputa. Niterói: Eduff, 2005.

SILVA, F. C. T. Cultura escolar: quadro conceitual e possibilidades de pesquisa. Educar, Curitiba, n. 28, p. 201-216, 2006.

SILVA, L. C. A prática de ensino de Física no ensino médio e o conceito de proporcionalidade: conexão fundamental na construção e (re)construção de conhecimentos. Belém: Instituto de Educação Matemática e Científica (IEMCI), Universidade Federal do Pará, 2009.

UNIVERSIDADE FEDERAL DO PARANÁ. Setor Litoral (UFPR Litoral). Projeto político pedagógico. 2008. Disponível em: <http://www.litoral. ufpr.br/sites/default/files/PPP\%20-\%20UFPR\%20-\%20LITORAL.pdf> . Acesso em: 10 jul. 2011.

ZULIANI, S. R. Q. A. Cultura, ciência, conhecimento químico e formação de valores: implicações para o conhecimento escolar. 2007. Disponível em <http://www.faac.unesp.br/extensao/forum/textos_ forum/silviazuliani.html $>$.

Lenir Maristela Silva, doutora em Ciências pela Universidade Federal do Paraná (UFPR), é professora de ensino superior na Universidade Federal do Paraná, Setor Litoral (UFPR Litoral), Matinhos, Paraná, Brasil.

lenirsilva@ufpr.br

Francéli Brizolla, doutora em Educação Inclusiva pela Universidade Federal do Rio Grande do Sul (UFRGS), é pró-reitora adjunta de graduação na Universidade Federal do Pampa (Unipampa), Bagé, Rio Grande do Sul, Brasil.

franbrizolla@hotmail.com

Luiz Everson da Silva, doutor em Química pela Universidade Federal de Santa Catarina (UFSC), é professor de ensino superior na Universidade Federal do Paraná, Setor Litoral (UFPR Litoral), Matinhos, Paraná, Brasil.

Recebido em 6 de setembro de 2011.

Aprovado em 4 de março de 2013. 